\title{
Birthweight of term infants and maternal occupation in a prospective cohort of pregnant
}

\section{women}

\author{
Alexandra Farrow, Katherine M Shea, Ruth E Little, and the ALSPAC study team
}

\begin{abstract}
Objective-To study the relation between birthweight of term infants and maternal occupation.

Methods-Information on job titles since the age of 16 , and sociodemographic and other lifestyle factors were obtained by means of questionnaires as part of the Avon longitudinal study of pregnancy and childhood (ALSPAC), from a cohort of 14000 pregnant women. The British 1990 standard occupational classification was used to code jobs within nine major job groups.

Results-For 9282 women who delivered term infants and reported $a$ job for the relevant period, there was a significant difference in mean birthweight among the nine major job groups. A $148 \mathrm{~g}$ difference was found between the mean birthweight of infants born to women with professional occupations and those with plant and machine operative jobs. Multiple regression analysis adjusted for sex of infant, parity, maternal height, smoking, caffeine consumption, and race. After adjustment the maternal job was no longer significantly associated with birthweight.
\end{abstract}

Conclusion-Despite the absence of a significant association between birthweight and job after adjustment, there were several findings which agreed with publications on maternal occupation and pregnancy outcome. The major job groups with the lowest birthweights included the following jobs: metal forming or welding, electric or electronic work, jobs in the textile trade, and assembling and working with equipment (mobile and stationary). The lack of an association may indicate that the study was of insufficient power to detect a small difference; it may indicate the presence of confounding variables that were not adjusted for or it may indicate that no association exists.

(Occup Environ Med 1998;55:18-23)

Keywords: birthweight; maternal occupation; prospective study

Publications on birthweight of different populations both within and between countries indicate that there has been interest in this variable over decades. Low birthweight is associated with increased perinatal mortality. It is also suggested that health status in later life may be influenced by low birthweight or its determining factors. ${ }^{1}$ One such factor may be maternal occupation around the period of conception or during the first trimester of pregnancy.

Over the past quarter of a century pregnant women have increasingly remained in the workforce. ${ }^{2}$ At the same time women have moved into a broader range of employment, much of which use new technologies. Despite the increasing time spent by women in the workplace, there have been few studies investigating the effects of specific maternal occupations on birthweight. ${ }^{3}$ Information on job groups associated with adverse birth outcomes may lead to identification of potentially toxic agents. Unfortunately information on maternal occupation in pregnancy is not routinely collected. The present paper describes the analysis of birthweights for term infants in the Avon longitudinal study of pregnancy and childhood (ALSPAC) in relation to the self reported maternal jobs. Most importantly, data collected prospectively have enabled possible confounding determinants of birthweight to be taken into account.

Studies of birthweight and specific maternal occupations have concentrated on medical and laboratory work; an early study among women physicians reported an increased risk of low birthweight among those exposed to anaesthetic gases. ${ }^{4} \mathrm{~A}$ large Canadian study that compared birth outcomes of 56000 women in 60 different industries, found low birthweight to be associated with maternal employment in food and drink manufacturing (relative risk (RR) 1.6), metal and electrical manufacturing (RR 1.5), cleaning or domestic work (RR 1.4), and clothing manufacturing (RR 1.2). ${ }^{5}$ This investigation also found increased preterm births among female psychiatric nurses (RR 2.5) and food and drink service workers (RR 1.3). ${ }^{6}$ An investigation of all live births in Scotland during a four year period ascertained occupation of $41 \%$ of mothers and $70 \%$ of fathers in the antenatal period. Significant risks of delivering a low birthweight infant were found for women who worked with electrical (RR 1.4) and leather products (RR 1.8) compared with other female manual workers. ${ }^{7}$ There was, however, no adjustment for maternal smoking status or other characteristics of this population. In a cohort of pregnancies of Danish physiotherapists low birthweight among male infants was associated with exposure to high frequency electromagnetic fields 
(OR 5.9). ${ }^{8}$ Women's work in the electronics industry and specifically in electronics assembly has also been significantly associated with delivering a low birthweight infant (OR 5.4) whereas infants of women working in the chemical industry showed higher rates of low birthweight and shorter gestation. ${ }^{10}$ Hairdressers working for more than 40 hours a week and standing for more than eight hours a day have also been reported as having an increased odds ratio for low birthweight. ${ }^{11}$

Other studies of the effects of women's work on reproductive outcome have reported no increased incidence of low birthweight. ${ }^{12-21}$ Most of these studies adjusted for potential confounders including age, smoking, and alcohol use but in others non-response and missing data made this difficult. ${ }^{11}$

Thus the literature on maternal occupation and infant birthweight is characterised by incomplete and often inconsistent findings. This may be partly due to inability to control for sociodemographic and behavioural characteristics of the population that in themselves may be associated with low birthweight. These include maternal ethnicity, social class, educational level, diet, height, reproductive history, age, marital status, smoking, alcohol, caffeine consumption, illegal substance misuse, family income, and prenatal care. Many of these characteristics may be associated with specific maternal occupations so that they could confound the results of occupational studies. The job also represents an aspect of social class. Traditionally the social class of the father in the United Kingdom population has been suggested as predictive of birthweight but a woman's job and consequently her own social status is highly correlated with that of her partner. Finally occupation in itself may point to exposures or tasks within a job that are of aetiological importance for an adverse pregnancy outcome. When occupation is used as a surrogate for workplace exposures to reproductive toxicants, misclassification may result. Thus the imprecise but strong association of occupation with other predictors of birthweight can result in conflicting evidence and inconclusive results.

\section{Method}

SUBJECTS

The ALSPAC is a prospective study of pregnancy outcome for women who had expected dates of delivery between 1 April 1991 and 31 December 1992, and who were resident in a defined geographical area of Avon in south west England. Women were invited to take part in several ways including posters in libraries, playgroups, healthcare settings, through the local media, and by direct contact with midwives and ALSPAC staff. Recruitment was by means of a self referral card returned to the study centre. The approximate number of births in this area for this period was 17500 ; $85 \%$ of this number, 14893 , enrolled in this study, of whom 14078 delivered live children. Stillborn infants, multiple births, and those with missing gestational age or missing birthweight were not included in the present analysis.

\section{DATA COLLECTION}

All the study variables (apart from birthweight and sex of infant, which were collected independently) were self reported by means of postal questionnaires. The first of four antenatal questionnaires was sent to the woman immediately after enrollment, usually in the first trimester. An occupational history was obtained at this time.

\section{STUDY VARIABLES}

\section{Occupation}

The first questionnaire in early pregnancy elicited information on the woman's occupational history since leaving school to the present, including each job title with dates of start and stop and details of any materials, machines, or chemicals used in each job. In this present study the primary independent variable was a woman's job reported in her job history within six months of conception or in the first trimester of the pregnancy, and identified by its British standard occupational classification (SOC) code. ${ }^{22}$ Job title and details of work in the pregnancy were also ascertained from a later questionnaire at 32 weeks. The job title was used as the best variable for determination of possible association between aspects of the woman's occupation and the birthweight of the infant. Information on specific exposure within the job is not presented in this paper.

The SOC is a job classification system developed by the United Kingdom Office of Population Census and Surveys (OPCS) updating the previous United Kingdom job classification systems, (OPCS 1980 Classification of Occupations and the Classification of Occupations and Directory of Occupational Titles, published in 1972). Occupations within this classification are seen as coherent sets of work activities carried out by individual people; occupational groups are defined by the type and level of skill required to carry out the major activities of the job. To apply an SOC code, a job is deemed to involve one occupation only so that a driver/ receptionist is classified as either a driver or a receptionist according to which work activity predominates. Specific jobs are coded into three digit codes between 101 and 990. These lie within nine major job groups and each of these major groups is made up of minor job groups (77 defined by two digit codes). In effect the name of the person's job (the job title) is the only tool required to code the occupation. The job title is not synonymous with social class but this can be assigned from the job title if the job status is also known-that is, manager, foreman etc. The information required to assess social class for the job titles was not available at this time point.

There were four coders in the United States within the National Institute of Environmental Health Sciences who were in close contact with the United Kingdom coder to establish consistent interpretation. Where there was any doubt 
about the appropriateness of the job code allocation OPCS was consulted for clarification as this was the first use of the new 1990 SOC. Reliability between raters of SOC coding of ALSPAC data was established and maintained at $\geqslant 95 \%$ agreement.

\section{Other variables}

Other independent variables in this study were included on the basis of the literature indicating their influence on fetal growth. Maternal age at last menstrual period was given in years and height in metres or feet (converted to inches). Maternal parity was reported as number of previous live births. Maternal ethnicity was coded under nine separate categories complying with the United Kingdom census form and converted to white versus non-white. Maternal education was recorded as the highest qualifications gained within the United Kingdom educational system and converted into four categories. Health behaviour variables included smoking, tea, coffee, cola, and alcohol consumption, and other drug misuse ascertained from questionnaires completed between 18 and 20 weeks of pregnancy. The number of cigarettes from zero to $\geqslant 30$ a day and the number of glasses of wine, beer, or spirits a week in the pregnancy were converted to five point scales. Daily caffeine intake $(\mathrm{mg})$ was calculated from the number of cups of tea $(27 \mathrm{mg})$, coffee $(59 \mathrm{mg})$, or cola $(33 \mathrm{mg})$ consumed in early pregnancy.

\section{Outcome variables}

Birthweight (g), as recorded in the delivery room, was abstracted from birth notifications. The last menstrual period as reported by the woman at enrolment, and the actual date of delivery were used to calculate the gestational age. Term birth was defined as birth on or after 37 completed weeks of gestation. All preterm deliveries were assessed to ensure that the categorisation had been supported by clinical estimates of dates during pregnancy.

\section{ANALYSIS}

The main aim of this analysis was to determine the association between women's reported job in the relevant period and the dependent variables of infant birthweight for a term birth. The analysis was limited to term births because the aetiology of a preterm birth is thought to be different from low birthweight term births. Initial analyses reported the term infants' mean unadjusted birthweights for the nine major job groups with analysis of variance (ANOVA). For these groups, the component minor jobs were examined. General linear modelling of birthweight and the job variable for term births was carried out with births to women in professional occupations as the baseline category. Firstly, multiple regression analysis was used to take secondary independent variables into account; these included sex of the infant, parity, marital status, maternal race, age, educational level, height, smoking, and caffeine and alcohol consumption in the pregnancy. Variables that did not significantly reduce the variance of the birthweight were dropped from the analysis. The effect of maternal job on birthweight was then determined by entering this variable into the model containing the relevant secondary variables: sex of infant, maternal parity, height, smoking, caffeine consumption, and race. The resulting adjusted birthweights were compared across the nine major job groups. The data were also stratified on paternal age and education to confirm that these did not alter the results. Finally, to obtain a measure of intrauterine growth we added gestational age (weeks) and gestational age squared to the model and repeated the analysis.

\section{Results}

Among the 14078 women in the ALSPAC cohort who delivered live singletons (term and preterm), 12042 completed the first questionnaire. Of these, 11662 women completed the job history question and 9893 reported being employed for the relevant period for this analysis of birthweight. The balance of 1769 women consisted of 301 women who reported themselves as housewives and 1468 women who reported themselves either as students, never worked, or unemployed. There were no significant differences among mean birthweights of these groups. In fact birthweight for those unemployed was only $16 \mathrm{~g}$ less than for those employed.

ANALYSIS OF TERM BIRTHWEIGHTS

Of the 9893 women who reported employment, 9282 gave birth to term infants. Table 1 shows the results of the ANOVA of unadjusted birthweight for the term births in this employed population. The ANOVA showed significant differences in the mean birthweights of the nine major occupational groups ( $F$ value =5.3, $\mathrm{P}=0.0001)$. The major occupational

Table 1 Unadjusted and adjusted mean birthweight of term infants for maternal job classified by major job group in descending order of unadjusted birthweight

\begin{tabular}{|c|c|c|c|c|c|c|}
\hline Major job group & Term infants $(n)$ & $\begin{array}{l}\text { Bwt unadjusted } \\
\text { (adjusted) }\end{array}$ & $S E$ & $\begin{array}{l}\text { Bwt mean v } \\
\text { reference }\end{array}$ & $95 \% C I$ & $P$ value \\
\hline Professional occupations & $846(788)$ & $3526(3268)$ & $16(26)$ & Reference & & \\
\hline Associate professional and technical & $1487(1397)$ & $3506(3277)$ & $13(23)$ & -20 & +19.6 to -59.6 & NS \\
\hline Sales occupations & $850(763)$ & $3492(3275)$ & $14(25)$ & -34 & +10.6 to -78.7 & NS \\
\hline Clerical and secretarial & $3190(2946)$ & $3470(3262)$ & $22(9)$ & -56 & -20.5 to -91.5 & 0.002 \\
\hline Personal and protective service occupations & $1106(983)$ & $3469(3275)$ & $15(24)$ & -57 & -14.6 to -98.6 & 0.0008 \\
\hline Managers and administrators & $877(804)$ & $3467(3271)$ & $15(16)$ & -59 & -14.3 to -102.9 & 0.0001 \\
\hline Craft and related occupations & $207(188)$ & $3416(3220)$ & $33(37)$ & -110 & -38.7 to -181.3 & 0.0025 \\
\hline Other occupations & $464(391)$ & 3407 (3259) & $25(29)$ & -119 & -65.6 to -171.8 & 0.0001 \\
\hline Plant and machine operatives & $255(210)$ & $3378(3239)$ & $33(36)$ & -148 & -82.1 to -213.5 & 0.0001 \\
\hline Totals & $9282(8470)$ & 3475 (3267) & & & & \\
\hline
\end{tabular}

^Adjusted for infant sex, parity, maternal height, smoking, caffeine consumption, and race. $\mathrm{SE}=$ standard error; Bwt=birthweight $(\mathrm{g})$. 
groups are tabled in order of descending birthweight. The heaviest mean birthweights were found in women reporting professional jobs and women in associate professional and technical jobs (nurses, etc). The lightest mean birthweights were for women working as plant and machine operatives, and were $148 \mathrm{~g}$ less (95\% confidence interval $(95 \%$ CI) 82.1 to 213.5) than the birthweights of infants born to women in professional jobs. Table 1 shows the differences between the mean (95\% CI) birthweight of each major job group and that of the professional group. The infants of clerical workers, women with personal and protective service jobs, and managers and administrators had similar mean birthweights.

In the regression analysis of term birthweight, the best model with the secondary independent variables included sex of infant, parity, maternal height, smoking, caffeine consumption, and race. When the major job code was entered as a categorical variable in the regression equation, it failed to contribute significantly to the variance in birthweight $(F=1.88, \mathrm{df}=8, \mathrm{P}=0.057)$. The greatest adjusted difference in birthweight was between the associate professional and technical group and the craft and related group ( $57 \mathrm{~g}$ ). The $t$ test for this pairwise comparison is not significant for these two major job groups $(P=0.09)$. After adjusting for the secondary independent variables, women in sales had heavier infants than professional women and those who were managers and administrators and the difference between the mean birthweights for all the groups were now smaller. Table 1 shows in italics the adjusted birthweights for each major job group. Adjustment for gestational age with gestational age and its square did not change these results.

We examined the constituent minor job groups within the major job groups. The major job group with the lowest birthweight babies after adjustment was craft and related. Within this major group the lowest birthweights among minor job groups were found among the electrical trades (3292 g) and metal machining ( $3123 \mathrm{~g}$ ). However, because of small numbers no attempt was made to calculate adjusted means for these minor job groups.

Table 2 shows some characteristics of women in major job groups with the largest and the smallest birthweight babies. This table is given to explain the importance of adjusting for confounding variables. Women in the professional job group were substantially taller, older, better educated, and more likely to be non-smokers than women in the other three groups.

RELIABILITY OF JOB TITLE FOR TERM BIRTHS

A job title reported in a questionnaire completed by the women at 32 weeks of gestation was used as a reliability check for information received from the job history completed in a questionnaire in the first trimester. The question requested the job title for current or most recent job. For the term births there were 8207 women who responded to both this and the earlier questionnaire. The $\kappa$ statistic for agreement on job title within the nine major job groups was 0.91 . Of these, 7883 women worked in the pregnancy. To establish whether the job reported at this point in the pregnancy would make any difference to these findings, a regression analysis of birthweight of term infants with this job title was carried out. The secondary independent variables of infant sex, parity, maternal height, smoking, caffeine consumption, and race were used. Job reported at 32 weeks gestation was then entered into the model but it failed to contribute significantly to the variance of birthweight $(F=0.82, \mathrm{df}=8$, $\mathrm{P}=0.59$ ).

Table 2 Demographic and other characteristics of women in professional occupations compared with associate professional and technical, plant and machine operatives, and craft and related occupations

\begin{tabular}{|c|c|c|c|c|c|c|c|c|}
\hline \multirow[b]{2}{*}{ Demographic and other characteristics } & \multicolumn{2}{|c|}{$\begin{array}{l}\text { Professional } \\
\text { occupations }\end{array}$} & \multicolumn{2}{|c|}{$\begin{array}{l}\text { Associate } \\
\text { professional and } \\
\text { technical }\end{array}$} & \multicolumn{2}{|c|}{$\begin{array}{l}\text { Plant and } \\
\text { machine } \\
\text { operatives }\end{array}$} & \multicolumn{2}{|c|}{$\begin{array}{l}\text { Craft and related } \\
\text { occupations }\end{array}$} \\
\hline & $n$ & $\%$ & $n$ & $\%$ & $n$ & $\%$ & $n$ & $\%$ \\
\hline \multicolumn{9}{|l|}{ Parity: } \\
\hline No previous live births & 394 & 47.0 & 754 & 51.6 & 116 & 49.4 & 86 & 41.4 \\
\hline Previous live births & 444 & 53.0 & 706 & 48.4 & 119 & 50.6 & 122 & 58.7 \\
\hline \multicolumn{9}{|c|}{ Maternal smoking status between $18-20$ weeks gestation: } \\
\hline Smoker & 59 & 7.0 & 208 & 14.2 & 96 & 40.7 & 66 & 31.7 \\
\hline Non-smoker & 788 & 93.0 & 1259 & 85.8 & 140 & 59.3 & 142 & 68.3 \\
\hline \multicolumn{9}{|l|}{ Maternal education: } \\
\hline None or few qualifications & 5 & 0.6 & 63 & 4.4 & 132 & 60.3 & 72 & 39.6 \\
\hline Exams passed at age 16 & 59 & 7.0 & 589 & 40.7 & 74 & 33.8 & 87 & 47.8 \\
\hline Exams passed at age 18 & 127 & 15.1 & 491 & 33.9 & 7 & 3.2 & 15 & 8.2 \\
\hline University degree & 649 & 77.3 & 304 & 21.0 & 6 & 2.7 & 8 & 4.4 \\
\hline \multicolumn{9}{|l|}{ Maternal age group: } \\
\hline$<20$ & 0 & 0 & 3 & 0.2 & 7 & 2.9 & 10 & 4.8 \\
\hline $20-24$ & 7 & 0.8 & 83 & 5.6 & 68 & 27.6 & 52 & 25.1 \\
\hline $25-29$ & 183 & 21.5 & 532 & 36.0 & 114 & 46.3 & 80 & 38.7 \\
\hline $30-34$ & 415 & 48.8 & 609 & 41.2 & 47 & 19.1 & 53 & 25.6 \\
\hline$>35$ & 246 & 28.9 & 253 & 17.1 & 10 & 4.1 & 12 & 5.8 \\
\hline \multicolumn{9}{|l|}{ Marital status: } \\
\hline Married & 741 & 87.4 & 1242 & 84.5 & 143 & 60.8 & 140 & 68.3 \\
\hline Other & 107 & 12.6 & 228 & 15.5 & 92 & 39.2 & 65 & 31.7 \\
\hline \multicolumn{9}{|l|}{ Maternal height (ft/in): } \\
\hline$<5 / 3$ & 142 & 17.4 & 276 & 19.3 & 64 & 29.1 & 48 & 24.5 \\
\hline $5 / 3-<5 / 5$ & 227 & 27.9 & 392 & 27.4 & 65 & 30.0 & 70 & 35.7 \\
\hline $5 / 5-<5 / 8$ & 309 & 37.9 & 545 & 38.0 & 68 & 30.9 & 58 & 29.6 \\
\hline$>5 / 8$ & 137 & 16.8 & 220 & 15.4 & 23 & 10.5 & 20 & 10.2 \\
\hline
\end{tabular}




\section{Discussion}

The results of our study showed no significant association between maternal job and infant birthweight once the relevant covariates were included in the analysis. These findings are consistent with other prospective studies of pregnancy outcome ${ }^{23}$ with epidemiological studies within specific environments ${ }^{15}$ and investigations of jobs from similar socioeconomic groups but with different exposures. ${ }^{21}$ Although this cohort of pregnant women is large, given the number of variables used in this analysis it has only limited power to detect small differences in birthweights between the nine major job groups. It is for this reason that it is necessary to be cautious in interpreting the finding of no significant association between maternal job and infant birthweight.

Historically the United Kingdom occupational classification systems were created for and are therefore more directly applicable to the classification of male jobs. Occupational data within these systems have been used to compare rates of disease, fertility, and mortality from disease notifications or from registrations of births for over a century. The 1990 SOC has been developed with some adjustments of structure to improve compatibility with the international standard classification of occupations. Several changes were also made to better reflect women's jobs. However, the job title may fail to give information on critical work and environmental exposures that have recently been reported as exerting a modest adverse prenatal influence on birthweight, preterm delivery, or small for gestational age births. These include environmental tobacco smoke, ${ }^{24}$ noise, ${ }^{525}$ shift work, ${ }^{56}$ ergonomic stressors, ${ }^{5728}$ and job control. ${ }^{29}$

Selection biases may exist both in recruitment and for those who were working. The participation rate of $85 \%$ of pregnant women in Avon during the study period was high as a result of the many different approaches to recruitment. Only limited comparison between the participants and non-participants has been possible. However, there was an underrepresentation of ethnic minorities in the cohort despite extensive recruitment efforts with materials translated into minority languages. Working women have been reported to have more favourable demographic and behavioural characteristics but less favourable reproductive histories. On the other hand, favourable reproductive outcomes have also been associated with women in employment. ${ }^{30} 31$ This is analogous to the healthy worker effect found among working men $^{32}$; women may be selected out of work if they have longstanding illness. ${ }^{33}$ Possible biases that may increase the likelihood of an adverse effect among women who are working include the unhealthy pregnant worker effect. This proposes that previous reproductive experience may affect the likelihood of entering and remaining in the workforce. The group of women who were employed in the relevant period in this study were significantly more likely to have some educational qualifications, to be older, taller, white, non-smokers, and have no previous pregnancies compared with those who were not employed. They were also more likely to have consumed some alcohol in the pregnancy but to have had lower total caffeine consumption. Data from unemployed women have not been presented. Women without a surviving infant may be more likely to continue working than other women who may be away from work while their children are young. ${ }^{34-37}$

It is of interest that both the major job groups plant and machine operatives and craft and related were found to have the lowest mean birthweights, before and after adjustment respectively, and have within their groups constituent minor job groups that have been associated with low birthweight in the scientific literature. ${ }^{59}$ These include metal forming or welding, electrical or electronic work, food preparation, jobs in the textile trade, assembling jobs, jobs operating vehicles, other jobs with machinery and equipment both mobile and stationary, and jobs assembling products. Assemblers or line workers may be involved in riveting, soldering, and wiring electronic equipment. If a real association with any job exists in these groups it might be masked by other determinants of birthweight that are also associated with the job. Or it might be that a particular exposure within some jobs cannot be distinguished by grouping all these jobs together. Although significant differences in birthweight were found in the unadjusted analysis it is clear that these disappeared when the analysis included the demographic and other characteristics. The focus of future studies should be on those jobs where a specific exposure has been implicated from a variety of studies and on the exposures themselves.

We are extremely grateful to all the mothers who took part and to the midwives for their cooperation and help in recruitment. The ALSPAC study team comprises interviewers, computer and laboratory technicians, clerical and research assistants, voland laboratory technicians, clerical and research assistants, volunteers, and managers, who made the study possible. The
project could not have been undertaken without the financial support of the Wellcome Trust, the Department of Health, the Department of the Environment, the Medical Research Council, and the National Institute of Environmental Health Sciences (NC, US), among others. We are also particularly grateful to Professors Allen Wilcox and Dale Sandler at NIEHS in North Carolina , Professor Jean Golding in the University of Bristol, and Professor Stephen Farrow in Middlesex University for their critical review of this work.

1 Barker DJ. Outcome of low birthweight. Horm Res 1994;42:223-30.

2 Moss N1, Carver K. Pregnant women at work: sociodemographic perspectives. Am f Ind Med 1993;23:541-57.

3 Office of Technology Assessment. Reproductive health hazards in the workplace. Washington DC:US GPO, 1985. Pharoah POD, Alberman E, Doyle P. Outcome of pregnancy among women in anaesthetic practice. Lancet 1977;i:34-6

5 McDonald AD, McDonald JC, Armstrong B, Cherry NM, Delorme C, Nolin AD, Robert D. Occupation and pregnancy outcome. Br F Ind Med 1987;44:521-6.

6 McDonald AD, McDonald JC, Armstrong B, Cherry NM, Nolin AD. Prematurity and work in pregnancy. $\mathrm{Br} f \mathcal{F}$ Ind Med 1988;45:56-62.

7 Sanjose S, Roman E, Beral V. Low birthweight and preterm delivery, Scotland, 1981-4: effect of parents' occupation. Lancet 1991;338:428-31.

8 Larsen AI, Olsen J, Svane O. Gender-specific reproductive outcome and exposure to high-frequency electromagnetic radiation among physiotherapists. Scand $\mathcal{f}$ Work Environ Health 1991;17:324-9.

9 Lipscomb JA, Fenster L, Wrensch M, Shusterman D, Swan S. Pregnancy outcomes in women potentially exposed to occupational solvents and women working in the electronics industry. F Occup Med 1991;33:597-604. 
10 Kallen B, Landgren O. Delivery outcome in pregnancies when either parent worked in the chemical industry. A study with central registries. F Occup Med 1994;36:563-8.

11 John E, Savitz D, Shy C. Spontaneous abortions among cosmetologists. Epidemiology 1994;5:147-55.

12 Savitz DA, Whelan EA, Kleckner RC. Effect of parents' occupational exposures on risk of stillbirth, preterm delivery and small for gestational-age infants. Am $\mathcal{F}$ Epidemiol 1989;129:1201-18.

13 Schaumburg I, Olsen J. Birth weight and gestational age among children of Danish pharmacy assistants. $\mathcal{F}$ Epidemiol Community Health 1991;45:49-51.

14 Fenster L, Coye MJ. Birthweight of infants born to Hispanic women employed in agriculture. Arch Environ Health 1990; 45:46-52.

15 Daniell WE, Vaughan TL, Millies BA. Pregnancy outcomes among female flight attendants. Aviat Space Environ Med 1990;61:840-4.

16 Olsen J, Hemminki K, Ahlborg G, Bjerkedal T, Kyyronen P, Taskinen $\mathrm{H}$. Low birthweight, congenital malformations Taskinen $\mathrm{H}$. Low birthweight, congenital malformations and spontaneous abortions among dry cleanin
Scand $\mathcal{F}$ Work Environ Health 1990;16:163-8.

17 Berlin M, Banks R, Catton M, Kazantzis G, Mottet NK, Berlin $M$, Banks R, Catton M, Kazantzis G, Mottet NK,
Samiullah Y. Birth weight of children and cadmium Samiullah Y. Birth weight of children and cadmium
accumulation in placentas of female nickel-cadmium accumulation in placentas of female nickel-cadmium 62.

18 Ericson A, Kallen B. Pregnancy outcome in women working as dentists, dental assistants or dental technicians. Int Arch Occup Environ Health 1989;61:329-33.

19 Schenker MB, Samuels SJ, Green RS, Wiggins P. Adverse reproductive outcomes among veterinarians. Am f Epidemiol 1990;132:96-106.

20 Seneviratne SR, Fernando DN. Influence of work on pregnancy outcome. Int $\mathcal{F}$ Gynaecol Obstet 1994;45:35-40.

21 Kanal E, Gillen J, Evans JA, Savitz DA, Shellock FG. Survey of reproductive health among female MR workers. Radiology 1993;187:395-9.

22 Standard occupational classification. 3 Vols. London: Employment Department Group, Office of Population Censuses ment Department

23 Rantakallio P. The longitudinal study of the northern Finland birth cohort of 1966. Paediatr Perinat Epidemiol 1988;2:59-88.
24 Fortier I, Marcoux S, Brisson J. Passive smoking during pregnancy and the risk of delivering a small-for-gestationalage infant. Am f Epidemiol 1994;139:294-301.

25 Nurminen T, Kurppa K. Occupational noise exposure and course of pregnancy. Scand $\mathcal{f}$ Work Environ Health 1989;15: $117-24$.

26 Nurminen T. Shift work, fetal development and course of pregnancy. Scand f Work Environ Health 1989;15:395-403.

27 Marbury MC. Relationship of ergonomic stressors to birthweight and gestational age. Scand 7 Work Environ Health weight and gestati

28 Henriksen TB, Hedegaard M, Secher NJ, Wilcox AJ. Standing at work and preterm delivery. Br $\mathcal{F}$ Obstet Gynaecol 1995;102:198-206.

29 Henriksen TB, Hedegaard $M$, Secher NJ. The relation between psychosocial job strain, and preterm delivery and low birthweight for gestational age. Int $\mathcal{f}$ Epidemiol 1994;23:764-74.

30 Murphy JF, Dauncey M, Newcombe R, Garcia J, Elbourne D. Employment in pregnancy: prevalence, maternal D. Employment in pregnancy: prevalence, maternal
characteristics, perinatal outcome. Lancet 1984;i:1163-6.

31 Saurel-Cubizolles MJ, Kaminski M. Work in pregnancy: its evolving relationship with perinatal outcome: a review. Soc Sci Med 1986;22:431-42.

32 Wen CP, Tsai SP, Gibson RL. Anatomy of the healthy worker effect: a critical review. f Occup Med 1983;25:2839.

33 Waldron I, Jacobs JA. Effects of labor force participation on women's health: new evidence from a longitudinal survey. $\mathcal{F}$ Occup Med 1988;30:977-83.

34 Selevan SG. Design considerations in pregnancy outcome studies of occupational populations. Scand $\mathcal{F}$ Work Environ Health 1981;7(supp 4):76-82.

35 Hemminki K, Nieme ML, Kyyronen P. Spontaneous abortions and reproductive selection mechanisms in the rubber and leather industry in Finland. Br f Ind Med 1983;40:816.

36 Lemasters GK, Pinney SM. Employment status as a confounder when assessing occupational exposures and spontaneous abortion. f Clin Epidemiol 1989;42:975-81.

37 Kallen B. Epidemiology of human reproduction. Boca Raton, Fl: CRC Press, 1988.

\section{Occupational and Environmental Medicine and the electronic age}

OEM has an Email address which is 100632.3615@compuserve.com. We welcome contact by Email, including letters to the editor. Some of our reviewers already send us their reports by Email, helping to speed up the peer review process.
Our publishing system is now fully electronic, and authors are sending their revised copy to us on disk as well as paper. Watch for revised Instructions to Authors.

The Editor 